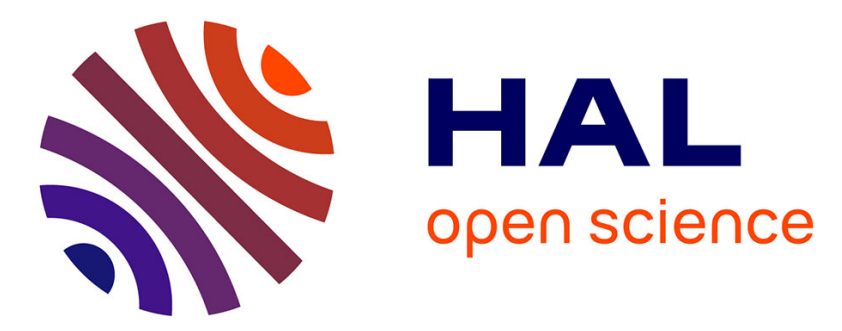

\title{
Pollination insights for the conservation of a rare threatened plant species, Astragalus tragacantha (Fabaceae)
}

Lucie Schurr, Laurence Affre, F. Flacher, Thierry Tatoni, L. Le Mire Pecheux, Benoit Geslin

\section{To cite this version:}

Lucie Schurr, Laurence Affre, F. Flacher, Thierry Tatoni, L. Le Mire Pecheux, et al.. Pollination insights for the conservation of a rare threatened plant species, Astragalus tragacantha (Fabaceae). Biodiversity and Conservation, 2019, 28 (6), pp.1389-1409. 10.1007/s10531-019-01729-4 . hal-02087562

\section{HAL Id: hal-02087562 https://hal.science/hal-02087562}

Submitted on 16 Sep 2019

HAL is a multi-disciplinary open access archive for the deposit and dissemination of scientific research documents, whether they are published or not. The documents may come from teaching and research institutions in France or abroad, or from public or private research centers.
L'archive ouverte pluridisciplinaire HAL, est destinée au dépôt et à la diffusion de documents scientifiques de niveau recherche, publiés ou non, émanant des établissements d'enseignement et de recherche français ou étrangers, des laboratoires publics ou privés. 


\title{
Pollination insights for the conservation of a rare threatened plant species, Astragalus tragacantha (Fabaceae)
}

\author{
L. Schurr $^{1}$ (D) . L. Affre ${ }^{1} \cdot$ F. Flacher ${ }^{1,2} \cdot$ T. Tatoni $^{1} \cdot$ L. Le Mire Pecheux ${ }^{3} \cdot$ B. Geslin $^{1}$
}

\begin{abstract}
The increase in habitat fragmentation impacts plant-pollinator interactions and threatens the sustainability of plant species. Astragalus tragacantha (Fabaceae), is a rare endangered plant species along the coastal habitats where the plant populations have undergone considerable fragmentation and decline of size. Controlled pollination treatments, the observation of pollinator activity, and pollinator captures, have been conducted to study: (1) the mating system of $A$. tragacantha and the potential for inbreeding depression and/or outbreeding depression based on controlled pollination treatments, (2) the pollinator composition among populations using a correspondence analysis and a hierarchical clustering, and (3) the link between pollinators and the plant reproductive success using a path-analysis model. In this study, we demonstrated that this plant was not autogamous self-pollinating and depended on pollinators for its reproduction. The absence of difference between manual and open pollinations regarding the reproductive success showed an absence of pollen limitation in our populations. We showed that populations differed in the composition of their pollinator guilds. Some pollinator species were predominant in certain populations. The pollination treatments revealed the existence of a mixed mating system in A. tragacantha populations. We showed an inbreeding depression potentially linked to a predominant pollinator-facilitated selfing, and the existence of outbreeding depression between some distant populations. These differences in pollinator guild and plant mating systems among populations must be considered during the restoration of populations along the Mediterranean coastal habitats in order to enhance the reproductive success and sustainability of $A$. tragacantha.
\end{abstract}

Keywords Mixed mating system · Pollination network · Plant reproductive success · Fragmented populations · Inbreeding and outbreeding depressions · Path analysis

L. Schurr

lucie.schurr@imbe.fr

Extended author information available on the last page of the article 


\section{Introduction}

Habitat fragmentation is considered to be one of the major causes of biodiversity erosion (Barnosky et al. 2012). Two main consequences of fragmentation are the decrease of population size and their spatial isolation (Wilcove et al. 1986; Fahrig 2003). Population fragmentation often leads to a decrease in the genetic variability due to inbreeding, genetic drift, and/or reduced gene flow (Aguilar et al. 2008). Particularly, among plants, pollen dispersion mediated by pollinators is affected by population size and isolation. Mating systems can thus evolve in response to habitat fragmentation. On the one hand, due to large distances separating plant populations, and creating barriers to pollinator foraging, reproduction may be favored within populations rather than between populations (Dick et al. 2008). The succeeding within-population crossings, according to plant density, can increase inbreeding and subsequent inbreeding depression and accentuate the loss of genetic diversity (Schemske and Lande 1985; Aizen et al. 2002; Aguilar et al. 2008). This loss decreases individual survival, reproductive success and adaptive potentialities (Crnokrak and Roff 1999, Frankham et al. 2014). On the other hand, habitat fragmentation could also favor between-population crossings. Pollinators can have to visit many flowers to fulfill the needs of their larvae for pollen. Small populations might not harbor enough resources, i.e., low plant density. In this case, pollinators might need to fly further away to find sufficient resources (Dick et al. 2008), increasing the eventuality of between-population crossings. In this context, to manage plant species conservation, the translocation of individuals favoring between-population crossings, i.e., the so-called "genetic rescue," may counteract the effects of inbreeding and inbreeding depression (Tallmon et al. 2004, Frankham et al. 2011, Frankham 2015). Hence, the increase in gene flow for endangered species has previously been reported as successful (Frankham 2015) whether the dispersal of new individuals was natural, e.g., Canis lupus in the Scandinavian Peninsula (Akkesson et al. 2016), or managed, e.g., Puma concolor coryi (Johnson et al. 2010) or Ranunculus reptans (Willi and Fischer 2005, see also the review of Whiteley et al. 2015). However, when fragmented populations have evolved differently in response to local conditions, between-population crossings are not always beneficial due to the disruption of local adaptations between populations, i.e., outbreeding depression (Frankham et al. 2011). Besides, events of outbreeding depression have been already synthetized for 40 plant and animal species in the literature (Edmands 2007; Frankham et al. 2011).

We focused on the sensitive coastal habitats in the Mediterranean Basin, one of the world's biodiversity hotspots (Médail and Myers 2004) and considered of particular interest from a conservation point of view (Médail and Quézel 1999). Within this habitat, in the French southern Mediterranean, the coastal phryganas community is one of the most fragmented and endangered plant formations (Affre et a1.2015). Astragalus tragacantha (Fabaceae) is a key species of this coastal phryganas community, spreading along the limestone coastal bedrock over a $10 \mathrm{~km}$ long and $100 \mathrm{~m}$ wide area (Affre et al. 2015). This rare plant species is restricted to a few capes and islands on the southern France, northern Spain and southeastern Portugal (Valsecchi 1994). Astragalus tragacantha is protected at the national level and designated as a conservation priority on the International Union for Conservation of Nature (IUCN) red list. In southern France, 96\% of its fragmented populations occur in Calanques National Park (Hardion et al. 2010, 2016). Because of the proximity with the city of Marseille (a large urban area of about one million inhabitants), A. tragacantha populations have suffered from major anthropogenic pressures, i.e., urban infrastructures (roads, buildings), human over frequentation (repeated tramplings), heavily 
inorganic-polluted soils and organic-polluted sea-sprays (Affre et al. 2015). The species shows a nearly complete absence of seedling recruitment and an increase of foliar necrosis and adult mortality, leading to a decline in population size (Affre et al. 2015). The species can persist on Trace Metal and Metalloid (TMM) contaminated soils in some populations (Laffont-Schwob et al. 2011; Salducci et al. 2019). To date, the potential for inbreeding and/or outbreeding depression, and pollinator activity have never been explored for A. tragacantha. However, these factors are crucial for effective reproduction and recruitment, and maintenance of populations. On the one hand, in the case of inbreeding depression, the sustainable maintenance of these populations is dependent to the efficiency of pollinators responsible for long-distance pollen dispersion, i.e., between-population crossings. On the other hand, if outbreeding depression exists, the between-population crossings can contribute to reduce individual survival. This highlights the importance of the composition and the efficiency of pollinators with regard to the reproductive success of A. tragacantha within and between populations. Finally, if a management for the reconnection of populations is to be achieved, knowing the mating system is meaningful to resolve the question of seed origin and mixture for the translocation of seedlings.

The aims of this study are therefore to determine for A. tragacantha (1) the mating system and the potential for inbreeding depression within population and/or outbreeding depression among populations, based on controlled pollination treatments, (2) the guild of pollinators among the populations using a correspondence analysis and a hierarchical clustering, and (3) the potential link between pollinator activity and the plant reproductive success using a path-analysis modelling. The results will bring additional knowledge to better understand the decline in population size and provide valuable advices for managers about the conservation of $A$. tragacantha populations, offering a new contribution towards the preservation of the Mediterranean coastal habitats.

\section{Materials and methods}

\section{Study species}

Astragalus tragacantha (Fabaceae) is restricted to a few capes and islands on the southern France, northern Spain and southeastern Portugal (Valsecchi 1994). In France, its populations are scattered along a coastline from Marseille, including the Frioul Islands, up to La Ciotat and La Seyne-sur-Mer (Hardion et al. 2010, 2016). This species is a thermoxerophilic halotolerant species limited to the rocky limestone soil of the coastline. It forms bushes measuring 20-30 cm high. It produces three-to-eight hermaphroditic white flowers (13-17 mm long) per branch from March to May. Fructification occurs from June to August. Each mature pod (9-10 mm long) produces 1-12 seeds. The fruits are mostly dispersed by barochory (gravity) and at a lesser degree by myrmecochory (ants). This species is adapted to harsh coastline environmental conditions, forming thorny cushions resistant to wind, with hairy leaves and spines to limit evapotranspiration.

\section{Study sites}

Six populations of Calanques National Park (Marseille, France) were chosen for the study: Saména (SA), Goudes (GO), Cap Croisette (CC), Marseilleveyre (MA), Escalette (ES) and Frioul (FR) (Fig. 1). Controlled pollination treatments were conducted in four of these six 


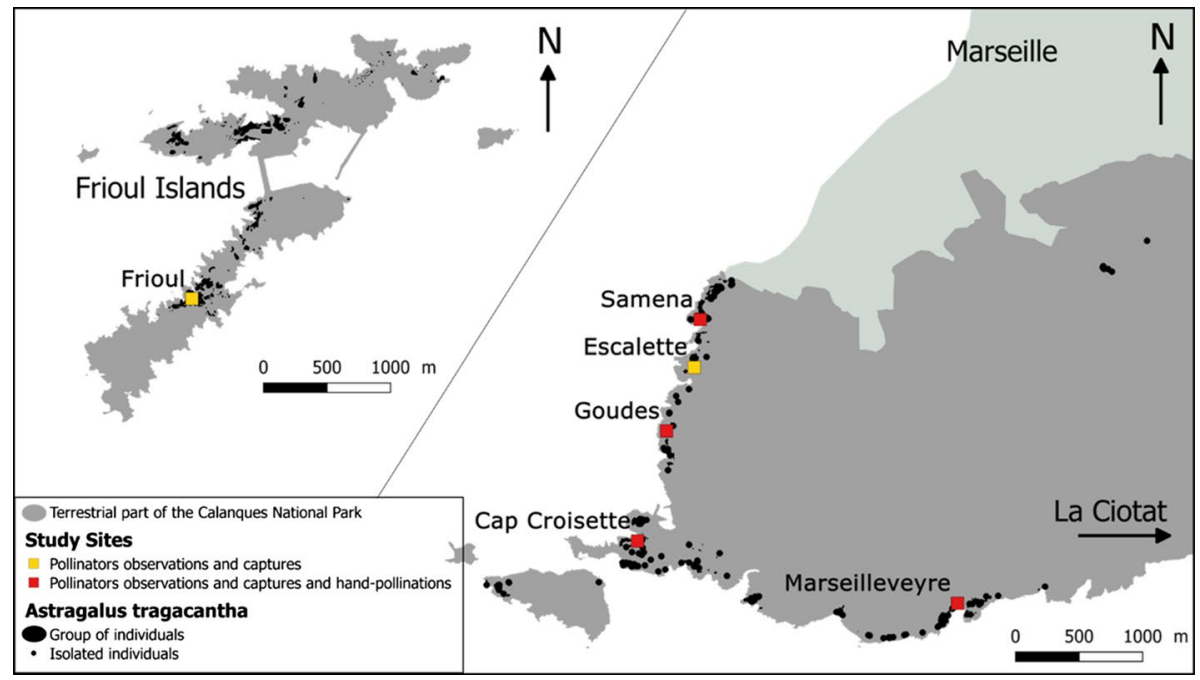

Fig. 1 Astragalus tragacantha populations in Calanques National Park (Marseille, France). (Color figure online)

populations (SA, GO, CC and MA), and the recording of the plant-pollinator interactions was conducted in all the six populations (Fig. 1). The between-population distances ranged from $350 \mathrm{~m}$ to $9 \mathrm{~km}$ (Fig. 1).

\section{Mating system and inbreeding or outbreeding depression}

\section{Controlled pollination treatments procedure}

To study the mating system of $A$. tragacantha, controlled pollination treatments were conducted within the SA, GO, CC and MA populations (Fig. 1). Within each population, 12-18 plants were haphazardly chosen at least five to ten meters apart from each other to increase the probability of having genetically distinct plants. In March 2017, five hand pollination treatments were performed on each of the chosen plants. A treatment was allocated to one to three flowers of one branch (according to the availability of open flowers on the branch) identified by a colored wool thread and colored markers on the calyx (i.e., one branch per treatment).

The treatments were as follows: (1) "Open Pollination" [OP] (control): the selection of one branch marked with no hand manipulation on floral buds and no bagging; (2) "auto-gamous selfing" [AS]: the selection of one marked branch with the bagging of floral buds to avoid pollinator intervention and no hand manipulation; (3) "manual selfing" [MS]: the selection of one marked branch with the bagging of floral buds and manual self-pollination with its own pollen; (4) "Manual Intrapopulation Outcrossing" [intraMO]: the selection of one marked branch with the bagging of floral buds, emasculation of stamens (i.e., the stamens are all removed using tweezers), and manual cross-pollination with pollen from flowers of other individuals within the same population; and (5) "Manual Interpopulation 
buds, emasculation of stamens and manual cross-pollination with pollen from flowers of individuals from each of the three other populations.

For cross-pollinations, the pollen donors came from three to five randomly collected flowers per plant on ten plants in each donor population. In total, we randomly collected approximately 40-50 flowers per population as donors which were then mixed together in a container (i.e., one container per population). Stamens were taken with a tweezers from containers and then rubbed on the treated flowers' stigma until pollen saturation. In total, crosses were performed on 859 flowers over treatments and populations (see details in Supplementary Material 1).

\section{Reproductive success among the controlled pollination treatments}

The fructification rate $(\%)$ was quantified. Due to warm weather, the fruits matured early in the season and were collected in May 2017. When the branches had a marked calyx without matured fruits (i.e., wilted flower, calyx without fruit), we considered these results to be a failure in the fructification process. However, when no mark on the calyx was present, we could not determine whether the fruit lost its mark during its development or did not develop; thus, the fruit was not considered a failure of fructification but rather missing data (NA). Among the 859 total treated flowers, 394 fruits were formed with 245 fruits harvested, but 304 did not develop and 161 were NA (Supplementary Material 2). We counted the total number of seeds per fruit and measured the total seed mass per fruit. Both parameters were then averaged per plant. The effect of the treatments, the populations and the interaction of both variables on the fructification rate per plant and the total number of seeds per fruit were tested using a Scheirer-Ray-Hare test (an extension of the Kruskal-Wallis test: non-parametric equivalent of 2-factor ANOVA with repetitions; package rcompanion, $\mathrm{R}$ software: $\mathrm{R}$ Core Team 2017 version 3.4.1). Then, a pairwise comparison using the "kruskalmc()" function (i.e., multiple comparison test between treatments, or treatments versus control, after Kruskal-Wallis test) was performed (package "pgirmess, R software: R Core Team 2017 version 3.4.1).

\section{Self-fertility (SF) and self-compatibility (SC) indices}

First, a self-fertility index (SF) was calculated following Suehs et al. (2005) as SF = AS seed set/(AS seed set + IntraMO seed set). Second, a self-compatibility index (SC) was similarly calculated following Suehs et al. (2005) as SC = MS seed set/(MS seed set + IntraMO seed set). Individuals with numerators and denominators both equal to 0 are considered as sterile (i.e., scored as 0). These indices were both calculated per individual then averaged per population. Indices of SF or SC equal to 0.5 indicate complete self-fertility or selfcompatibility (Suehs et al. 2005). Values between 0 and 0.5 represent partial self-fertility or self-compatibility, whereas values above 0.5 indicate preferentially self-fertile or selfcompatible (Suehs et al. 2005). A one-tailed t test was used to compare the mean of the SF and SC indices to the threshold of 0.5.

\section{Inbreeding (RPos) and outbreeding (RPwb) depressions}

The relative performance of outcross (o) or self (s) pollinations (RPos), i.e., an inbreeding depression index (RPos), was calculated per plant, and then averaged per population, following Agren and Schemske (1993) as RPos $=(\mathrm{Wo}-\mathrm{Ws}) / \mathrm{Wmax}$. Ws is the performance 
in terms of self-generated progeny. Wo is the performance in terms of outcrossed progeny. $\mathrm{Wmax}=\mathrm{Ws}$ when the selfing performance is greater than the outcrossing performance, or Wmax $=$ Wo when the outcrossing performance is greater than the selfing performance. Following Campagne et al. (2008), the product "total number of seeds per fruit $\times$ total mass of seeds per fruit" was used as a cumulative reproductive performance (W). If RPos is lower than 0 , the selfing performance is greater than the outcrossing performance. If RPos is greater than 0 , the selfing performance is lower than the outcrossing performance. An index of RPos significantly higher than the threshold of 0.5 shows evidence of an inbreeding depression (Agren and Schemske 1993). One-tailed t tests were used to compare the mean of the RPos index to the threshold of 0 and the threshold of 0.5 ( $\mathrm{R}$ software: R Core Team 2017 version 3.4.1).

In parallel, the relative performance between the outcrossing performance within populations (w) and between populations (b) for each pair of population studied, i.e., an outbreeding depression index (RPwb), was calculated per plant, and then averaged per population following Campagne et al. (2008). This RPwb index was calculated as $\mathrm{RPwb}=(\mathrm{Ww}-\mathrm{Wb}) / \mathrm{Wmax}$. $\mathrm{Ww}$ is the outcrossing performance within population descendants. $\mathrm{Wb}$ is the outcrossing performance between population descendants. $\mathrm{Wmax}=\mathrm{Wb}$ when the between-population crossing performance is greater than the withinpopulation crossings, or $\mathrm{Wmax}=\mathrm{Ww}$ when the within-population crossing performance is greater than the between-population crossings. If RPwb is lower than 0 , the within-population outcrossing performance is lower than the between-population outcrossing performance. If RPwb is greater than 0 , the within-population outcrossing performance is greater than the between-population outcrossing performance, named outbreeding depression. A one-tailed t-test was used to compare the mean RPwb indices to the threshold of 0 (R software: R Core Team 2017 version 3.4.1).

\section{Composition of pollinators among populations}

\section{Pollinators guild}

To describe the $A$. tragacantha pollinator guild and efficiency, 12-14 plants were selected in each of the six populations, i.e., 12 in CC, GO and ES; 13 in SA; and 14 in MA and FR (for a total of 77 plants).

For two periods, one in March and one in April 2017, we observed each plant on noncloudy days between 9:00 am and 17:30 pm (with a minimal temperature of $12{ }^{\circ} \mathrm{C}$ ). Half of the plants were observed in the morning and half in the afternoon in the first period and inversely for the second one.

For each observation, the air temperature $\left({ }^{\circ} \mathrm{C}\right)$, the mean wind speed $(\mathrm{km} / \mathrm{h})$ and the cloud cover $(\%)$ were recorded. For each plant, we first observed pollinator interactions during a bout of 10 min per period (20 min adding the two periods). During this observation bout, the abundance and richness of pollinators were recorded per plant. Second, we captured each pollinator in interaction with A. tragacantha flowers using a net during another bout of $10 \mathrm{~min}$ per period (20 min adding the two periods). Capture bouts were only performed if at least one interaction was observed during the first observation bout. A few plants were observed a single time because they were not in bloom anymore in April (10 among the 77 plants). For the statistical analysis, we only kept individuals that were observed for the two periods (i.e., 67 plants). 
We considered an interaction when an insect landed on a flower, opened the keel and plunged the head into the flower. Observed pollinators have been classified into nine easily recognizable morphological groups as follows: "large solitary bees" $(>1 \mathrm{~cm})$, "small solitary bees" ( $<1 \mathrm{~cm})$, "domestic bees" (Apis mellifera), "bumblebees", "Lepidoptera", "Syrphydae", "Bombylidae", "Coleopterae", and "other Dipterae". Captured pollinators were then identified to the genus level with a binocular magnifier and determination keys (Terzo and Rasmont 2016) and to the species level by professional taxonomists (see "Acknowledgments").

The variation in the distribution of pollinator species captured was illustrated with a Correspondence Analysis (CA; the equivalent of a principal component analysis for count data) followed by a hierarchical clustering (AHC). The R software (R Core Team 2017 version 3.4.1) was used to perform the correspondence analysis (package ade4) and the hierarchical clustering (packages ade4 and stats). For this CA, rare species, i.e., captured in less than two populations, were removed to avoid the overestimation of the weight of rare species in the analysis.

\section{Reproductive success among populations}

For the six populations, i.e., CC, ES, FR, GO, MA and SA, we estimated the reproductive success of every 12-14 observed plants by counting their total number of fruits per plant, and their total number of seeds per fruit then averaged per plant. First, the length $(\mathrm{m})$ and width $(\mathrm{m})$ of each plant were measured to calculate their area ' $\mathrm{X}$ ' $\left(\mathrm{m}^{2}\right)$. Second, the number of branches ' $\mathrm{Y}$ ' was counted in a $40 \times 40 \mathrm{~cm}$ quadrat (corresponding to an area of $0.16 \mathrm{~m}^{2}$ ). The number of branches in the plant was then estimated with the cross product $(\mathrm{X} \times \mathrm{Y}) / 0.16$. Third, the fruits were exhaustively counted on ten branches per plant, and the mean number of fruits per branch ' $Z$ ' was calculated. Finally, we extrapolated the total number of fruits per plant following the formula $[(\mathrm{X} \times \mathrm{Y}) / 0.16] \times \mathrm{Z}$. Three to five fruits per observed plant were then harvested (i.e., 372 fruits; Supplementary Material 1) and opened to calculate the mean of the total number of seeds per fruit for each plant.

Differences between populations for the number of fruits per plant were tested using a Kruskal-Wallis test $(\mathrm{K}-\mathrm{W})$ followed by a pairwise comparison post hoc test using the "kruskalmc()" function (R software: R Core Team 2017 version 3.4.1). Differences between populations for the total number of seeds per fruit for each plant were tested using ANOVA followed by a pairwise comparison using the Tukey post hoc test ( $\mathrm{R}$ software: $\mathrm{R}$ Core Team 2017 version 3.4.1).

\section{Link between pollinators and the plant reproductive success}

\section{Plant attractiveness}

To estimate the attractiveness of individual plants to pollinators, for each observation/capture bout on the 12-14 observed plants, the total number of flowers per plant was assessed with a $40 \times 40 \mathrm{~cm}$ quadrat divided into 16 sub-quadrats. We estimated the size of plants by calculating the volume of each plant by measuring individual length, width and height (in m) using a tape measurer. 


\section{Site attractiveness}

For each population, in an eight $\mathrm{m}^{2}$ circular quadrat centered on the 12-14 observed plants, we estimated the number of co-flowering plant species and their floral cover (\%) excluding $A$. tragacantha to analyze its relative attractiveness compared with other coflowering plant species.

\section{Path-analysis setting}

The pollination of a plant is a complicated process, and several variables can impact it. It might be complex to determine the causal structure of the system. We thus tested the causal structure of several variables using a path-analysis (structural equation modelling, i.e., SEM; Lefcheck 2016). SEM is a probabilistic model that joins multiple predictor and response variables in a single causal network. This method provides a way to obtain causal relationships, and not just correlations, between variables (Lefcheck 2016). In other terms, one particularity of structural equation modelling (path analysis) is formulating an informal hypothesis about the causal structure of the model by using a pre-existing hypothesis that A causes B. "Piecewise SEM" package (R software: R Core Team 2017 version 3.4.1) thus provides a method to test whether the assertion of the whole path is correct, and if it is correct, it allows us to explicitly test the hypothesis that A causes B (Lefcheck 2016). To assess the overall fit of each SEM, we need to estimate that all the combined probability of the missing paths did not deviate from conditional independence expectations. We used Shipley's test of d-separation (Shipley 2009, 2013; Lefcheck 2016; Ogilvie et al. 2017). The $d$-separation test generates a Fisher's $C$ test statistic, which can be used to assess overall fit of the SEM (Shipley 2009, 2013; Lefcheck 2016):

$$
\mathrm{C}=-2 \sum_{i=1}^{k} \ln (p \mathrm{i})
$$

where $p_{i}$ is the ith independence claim in a basis set consisting of $k$ claims. The C statistics can be then compared to a $\chi^{2}$ distribution with $2 k$ degrees of freedom (Shipley 2009 , 2013; Lefcheck 2016; Geslin et al. 2017). The hypothesized relationships are considered to be consistent with the data when the collection of the relationships represented by $C$ could have occurred by chance, in which case the $\mathrm{p}$ value for the $\chi^{2}$ test is greater than the threshold 0.05, and the path model is rejected if the p value is $<0.05$ (Shipley 2009, 2013; Lefcheck 2016; Geslin et al. 2017).

We calculated eight partial correlations (package "ppcor", R software: R Core Team 2017 version 3.4.1) controlling for all other variables: (1) the partial correlation between the number of co-flowering plant species per eight $\mathrm{m}^{2}$ circular quadrat and the floral cover per quadrat (\%); (2) between the floral cover per quadrat (\%) and the total number of flowers per plant; (3) between the total number of flowers per plant and the total number of fruits per plant; (4) between the total number of flowers per plant and the plant volume $\left(\mathrm{m}^{3}\right)$; (5) between the total number of fruits per plant and the plant volume $\left(\mathrm{m}^{3}\right)$; and $(6$, 7 and 8) between the three weather parameters with each other (temperature $\left[{ }^{\circ} \mathrm{C}\right]$ with wind speed $[\mathrm{km} / \mathrm{h}]$, temperature with cloud cover [\%], and wind speed with cloud cover). Only the total number of fruits per plant was correlated to the plant volume $(\mathrm{Rho}=0.646$; 
$\mathrm{p}<0.05)$. We thus decided to only keep the number of fruits per plant for the subsequent models.

The path-analysis was then set up with the following variables: (1) the "plant volume," (2) the "co-flowering number of plant species per eight $\mathrm{m}^{2}$ circular quadrat," (3) the "floral cover per quadrat," (4) the "total number of flowers per plant," (5) the "pollinator abundance per plant," (6) the "pollinator richness per plant," (7) "the total number of fruits per plant," and (8) the "mean number of seeds per fruit" using linear models (R software: R Core Team 2017 version 3.4.1, package lme4). The best models were selected on the basis of the comparison of their AICc (Akaike Information Criterion) and missing paths were added. After model simplifications, only the seven best models (see details of the seven selected models, path-analysis setting and results in the Supplementary Material 3) were kept to settle our path-analysis ( $\mathrm{R}$ software: R Core Team 2017 version 3.4.1, package piecewiseSEM; Lefcheck 2016) studying the links between each variable for A. tragacantha reproductive system following the Shipley Method (Shipley 2009, 2013). In this paper, we underlined the models explaining the reproductive success of A. tragacantha, i.e., with the total number of fruits per plant and the total number of seeds per fruit averaged per plant as response variables.

\section{Results}

For each calculated mean, a standard deviation (noted mean \pm SD) and/or a 95\% confidence interval were quantified (noted mean, 95\% CI [range min; range max]). All modelled effects were indicated with their standard deviation (noted estimate \pm SD).

\section{Mating system and inbreeding or outbreeding depression}

\section{Controlled pollination treatments procedure}

To precise the mating system of $A$. tragacantha, we manually treated 859 flowers and harvested 245 fruits (Supplementary Material 2). On average, $1.35 \pm 0.81$ mature seeds per fruit were collected with a mean mass of $1.28 \pm 1.83 \mathrm{mg}$ per fruit. We collected a mean of $23 \pm 14 \%$ of fruits with zero seed i.e., empty fruit (21-50\% according to treatments; Supplementary Material 1). The Scheirer-Ray-Hare test showed significant differences among the treatments for the fructification rate $(\mathrm{H}=112.53$, ddl $=7, \mathrm{p}<0.001)$ and the total number of seeds per fruit $(\mathrm{H}=77.80, \mathrm{ddl}=7, \mathrm{p}<0.001)$. The Scheirer-Ray-Hare test also showed significant differences among the populations for the fructification rate $(H=20.06$, $\mathrm{ddl}=3, \mathrm{p}<0.001)$. No significant variation in the fructification rate $(\mathrm{H}=15.28, \mathrm{ddl}=17$, $\mathrm{p}>0.05)$ or the number of seeds per fruit $(\mathrm{H}=15.38, \mathrm{ddl}=17, \mathrm{p}>0.05)$ were observed according to the interaction between treatments and populations. The pairwise comparisons showed that the GO population have a smaller fructification rate than the CC and SA populations.

The pairwise comparisons also showed that the autogamous selfing (AS) treatment led to a lower fructification rate $(\mathrm{p}<0.05$, Fig. $2 \mathrm{a})$. Except for the interMOgo treatment $(p>0.05)$, the AS treatment led to fewer seeds per fruit $(p<0.05$, Fig. $2 b)$. These comparisons also showed that the fructification rate per plant was smaller for the Open Pollination (OP) treatment compared with the Manual Interpopulation Outcrossing treatment with GO population pollen (interMOgo, p <0.05, Fig. 2a). 


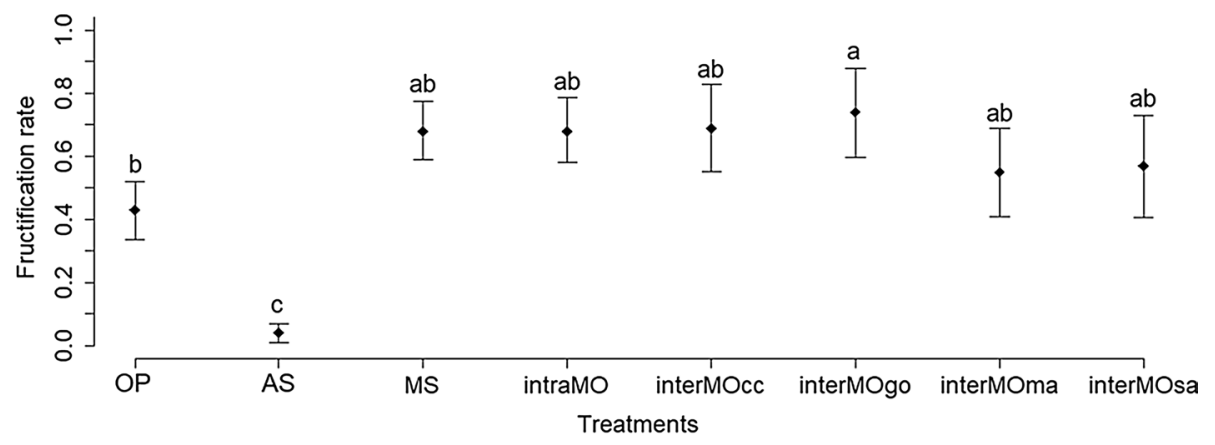

(a)

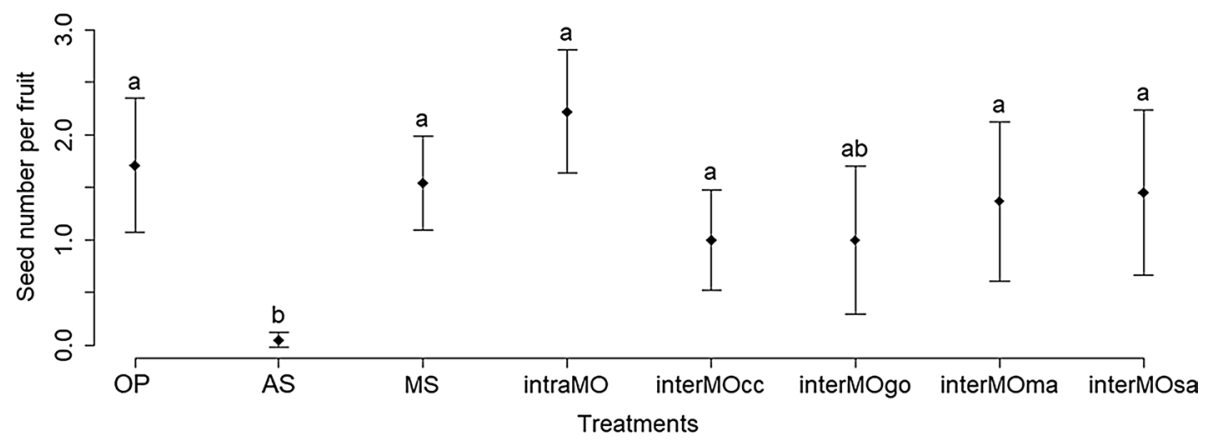

(b)

Fig. 2 a Fructification rate (\%) per plant, and $\mathbf{b}$ total number of seeds per fruit (averaged per plant) according to controlled pollination treatments. Vertical bars represent the $95 \%$ confidence interval. $O P$ open pollination, $A S$ autogamous selfing, $M S$ manual selfing, intraMO manual intrapopulation outcrossing, interMOcc, go, ma, sa manual inter-population Outcrossing with CC population, GO population, MA population, and SA population

\section{Self-fertility (SF) and self-compatibility (SC) index}

For all populations, the t-tests showed that the self-fertility values were significantly different from $0.5(\mathrm{CC}: \mathrm{t}=-5.50, \mathrm{p}<0.001$; GO: $\mathrm{t}=-\infty, \mathrm{p}<0.001$; MA: $\mathrm{t}=-\infty, \mathrm{p}<0.001$; $\mathrm{SA}: \mathrm{t}=-21.50, \mathrm{p}=0.001$ ) but equal or very close to 0 (between 0 and 0.08 ), indicating that $A$. tragacantha is very lowly self-fertile. The mean number of seeds per fruit in the AS treatment is negligible (Fig. 2b). Moreover, the t-tests showed that the self-compatibility values are significantly different from 0.5 only for the GO population $(\mathrm{t}=-3.11$, $\mathrm{p}<0.05$; Fig. 3a), indicating that A. tragacantha is completely self-compatible in most of the populations.

\section{Inbreeding (RPos) and outbreeding (RPwb) depressions}

The GO population was the only one population presenting an inbreeding depression index (RPos) significantly greater than $0(\mathrm{t}=2.60, \mathrm{p}<0.05)$ but not significantly different from $0.5(t=-0.25, p>0.05$; Fig. $3 b)$. The inbreeding depression index did not significantly 
Fig. 3 a Self-compatibility index (SC) according to populations, and $\mathbf{b}$ relative performance between out- and self-crossings within populations (RPos) as an inbreeding depression index according to populations. Vertical bars represent the $95 \%$ confidence interval. The black and red dotted line indicate respectively the 0 and 0.5 thresholds above which there is self-compatibility (black, a) or inbreeding depression (black and red, b). CC Cap Croisette population, $G O$ Goudes population, MA Marseilleveyre population, $S A$ Saména population; "*” $t$ test significant difference between a SC and 0.5 and b RPos and 0 (black star) or 0.5 (red star). (Color figure online)

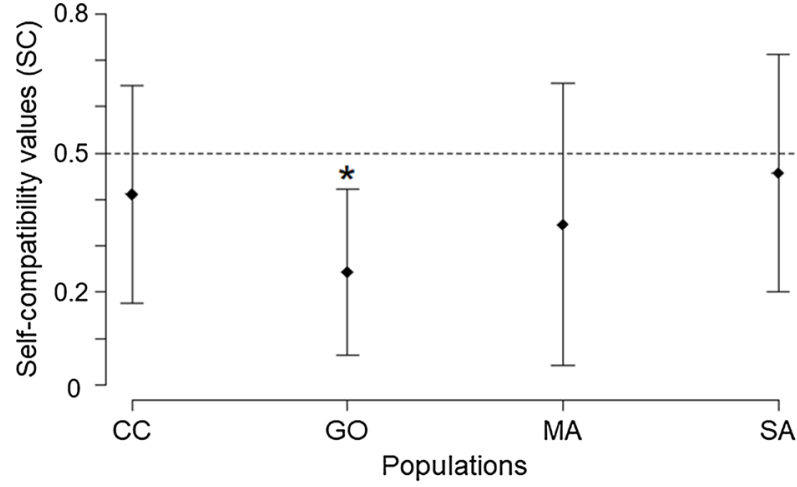

(a)

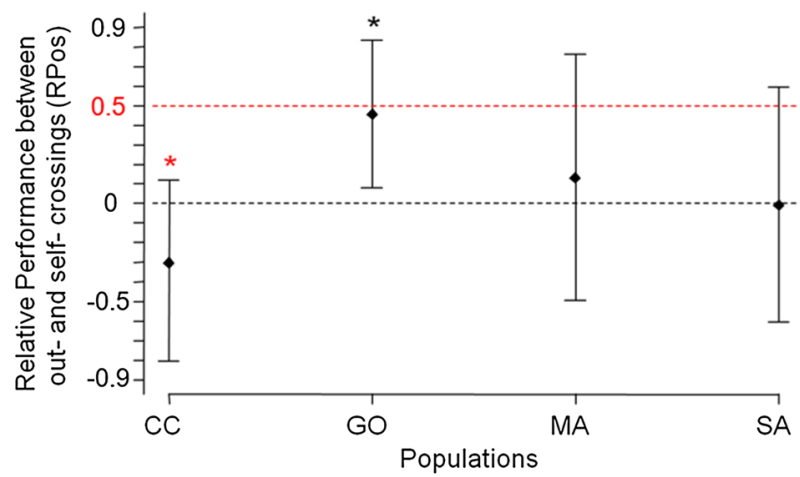

(b)

differ from 0 for all other populations (Fig. 3b). The inbreeding depression index also did not significantly differ from 0.5 for the MA and SA populations (Fig. 3b).

The outbreeding depression index (RPwb) was significantly greater than 0 for the $\mathrm{CC}$ population only in the GO and MA populations $(\mathrm{t}=2.88, \mathrm{p}<0.05$ and $\mathrm{t}=2.70, \mathrm{p}<0.05$, respectively; Table 1).

\section{Composition of pollinators among populations}

\section{Pollinators guild}

Pollinator activity was observed in all six populations (CC, ES, FR, GO, MA and SA) during a cumulative time of $24 \mathrm{~h}$. We recorded 4798 interactions between A. tragacantha and the local wild pollinating fauna. In particular, 3897 interactions were performed by solitary bees, 714 by Bombus terrestris, 55 by Apis mellifera, 35 by the Lepidoptera Macroglossum stellatarum and 97 by Diptera. We captured pollinators for a cumulative time of $20 \mathrm{~h}$ and $20 \mathrm{~min}$ for the six populations. We caught 249 pollinators from 13 genera or families (Andrena, Anthophora, Apis, Bombus, Diptera, Eucera, Macroglossum, Megachile, Osmia, Rhodanthidium, Syrphydae, Tenthredo, Vespidae) and from 17 identified species (plus 3 unidentified species; see Supplementary Material 4). Eucera 
Table 1 Relative performance between within- and betweenpopulation crossings (RPwb) as an outbreeding depression index according to populations

\begin{tabular}{llll}
\hline $\begin{array}{l}\text { Donor } \\
\text { population }\end{array}$ & $\begin{array}{l}\text { Recipient } \\
\text { population }\end{array}$ & RPwb (mean $[95 \%$ CI $])$ & $\begin{array}{l}\text { Student } t \text { test } \\
\text { p value }\end{array}$ \\
\hline CC & GO & $+0.145[-0.314 ; 0.684]$ & $0.553(\mathrm{~ns})$ \\
& MA & $+0.248[-0.571 ; 1.066]$ & $0.226(\mathrm{~ns})$ \\
& SA & $+0.294[-2.494 ; 3.083]$ & $0.872(\mathrm{~ns})$ \\
GO & CC & $+0.545[0.108 ; 0.983]$ & $0.021 *$ \\
& MA & $+0.409[-0.332 ; 1.150]$ & $0.472(\mathrm{~ns})$ \\
& SA & $+0.091[-2.061 ; 2.244]$ & $0.326(\mathrm{~ns})$ \\
MA & CC & $+0.587[0.072 ; 1.101]$ & $0.031 *$ \\
& GO & $+0.194[-0.338 ; 0.726]$ & $0.430(\mathrm{~ns})$ \\
& SA & $+0.477[-0.819 ; 1.773]$ & $0.694(\mathrm{~ns})$ \\
SA & CC & $+0.155[-0.490 ; 0.800]$ & $0.589(\mathrm{~ns})$ \\
& GO & $+0.419[-0.062 ; 0.904]$ & $0.084(\mathrm{~ns})$ \\
& MA & $-0.015[-0.941 ; 0.910]$ & $0.968(\mathrm{~ns})$ \\
\hline
\end{tabular}

Student's t test was performed to compare RPwb values with a threshold of 0 above which there is outbreeding depression

$C C$ Cap Croisette population, $G O$ Goudes population, $M A$ Marseilleveyre population, $S A$ Saména population, $R P w b$ performance between the outcrossing performance within subpopulations (w) and between subpopulations (b) with a $95 \%$ confidence interval

caspica, Anthophora plumipes, Rhodanthidium sticticum, Andrena similis and Osmia bicornis represented the most abundant species within their respective genera (Supplementary Material 4). In the correspondence analysis (CA) linking species and populations, we conserved the first 2 axes (explaining respectively $36.89 \%$ and $32.08 \%$ of the total inertia; Fig. 4 and Supplementary Material 5). Some pollinator species were predominant in certain populations., i.e., the GO population is dominated by Bombus terrestris captures, the CC population by Anthophora plumipes and the FR population by Eucera caspica (Fig. 4; Supplementary Material 5). The MA, SA and ES populations did not show any link with a particular dominant pollinator species (Fig. 4; Supplementary Material 5). The hierarchical clustering showed similar pollinating guilds for the ES and SA populations and the FR and MA populations (Supplementary Material 5).

\section{Reproductive success among populations}

The mean number of fruits per plant was equal to $7800.99 \pm 6466.19$, and the mean per plant of the total number of seeds per fruit was equal to $2.17 \pm 1.26$. Among the 372 harvested fruits, 75 did not have any seeds i.e., empty fruit (20\%; Supplementary Material 1). The Kruskal-Wallis results showed significant differences among populations for the number of fruits per plant $(\mathrm{H}=11.75$, ddl $=5, \mathrm{p}<0.05$, Fig. 5a) and the total number of seeds per fruit averaged per plant $(\mathrm{F}=2.55, \mathrm{ddl}=5, \mathrm{p}<0.05)$. The post hoc tests did not confirm the difference between populations for the number of fruits per plant, but they showed that only the GO population produced significantly more seeds per fruit than the MA population $(t=2.85, \mathrm{p}<0.05$; Fig. $5 \mathrm{~b})$ and marginally more seeds per fruit than the SA population $(t=2.68, p=0.05$; Fig. $5 b)$. 


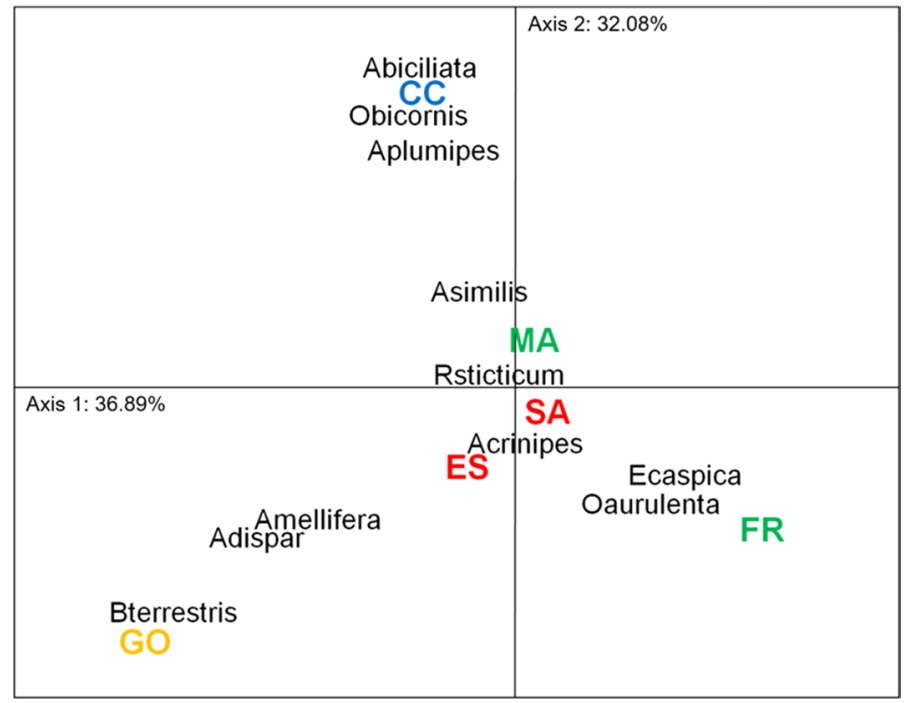

Fig. 4 Correspondence analysis of species captures distribution among A. tragacantha populations in Calanques National Park. Different colors distinguish different groups following a hierarchical clustering. Populations in the same color have a similar pollinator guild according to the hierarchical clustering (i.e., MA and FR population and ES and SA population). CC Cap croisette population, ES Escalette population, $F R$ Frioul population, $G O$ Goudes population, MA Marseilleveyre population, $S A$ Saména population, Asimilis: Andrena similis, Aplumipes: Anthophora plumipes, Acrinipes: Anthophora crinipes, Abiciliata: Anthophora biciliata, A.dispar: Anthophora dispar, Amellifera: Apis mellifera, Bterrestris: Bombus terrestris, Ecaspica: Eucera caspica, Oaurulenta: Osmia aurulenta, Obicornis: Osmia bicornis, Rsticticum: Rhodanthidium sticticum. (Color figure online)

\section{Link between pollinators and the plant reproductive success}

The path-analysis model for the pollination system of A. tragacantha explained our data adequately (Fisher's $\mathrm{C}=47.52, \mathrm{k}=36, \mathrm{p}>0.05$ ). We expected an influence of the pollinator abundance and richness on the fruit set and the seed set. This path analysis showed that the pollinator parameters did not influence the number of fruits per plant, but they influenced the total number of seeds per fruit (Fig. 6, Supplementary Material 3).

The increase in the pollinator abundance and the number of fruits per plant significantly increased the number of seeds per fruit $(b=+0.49 \pm 0.17, p<0.01$ and $b=+0.23 \pm 0.12, p<0.05$, respectively; Fig. 7a). A decrease in the pollinator richness per plant significantly decreased the number of seeds per fruit $(b=-0.27 \pm 0.11$, $\mathrm{p}<0.05$; Fig. 7b).

\section{Discussion}

The first important feature of our study was that Astragalus tragacantha was completely dependent on pollinators for its reproduction. Some populations showed inbreeding or outbreeding depression. The second feature was that its populations differed in the composition of pollinator guild and some pollinator species were predominant in certain 


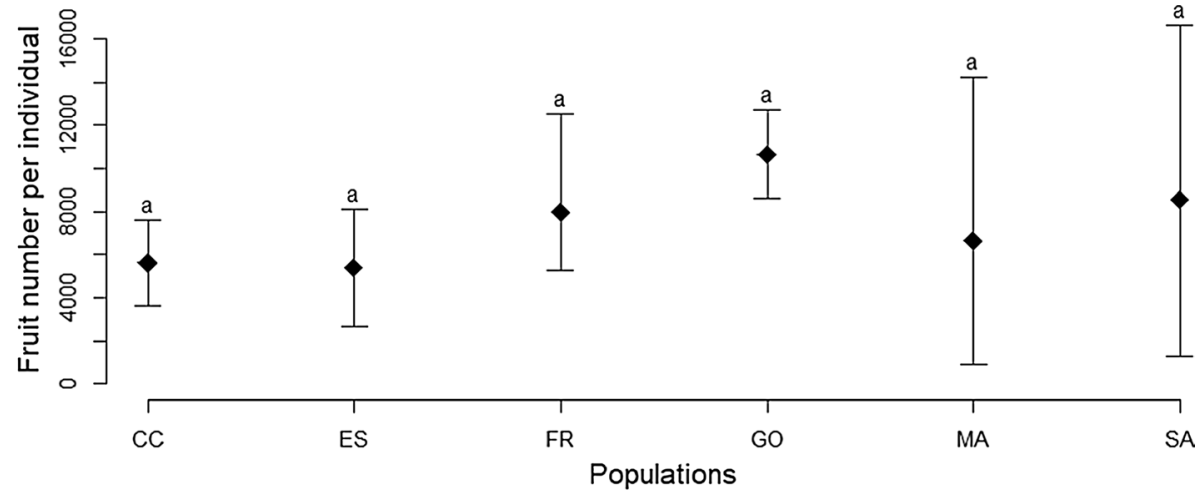

(a)

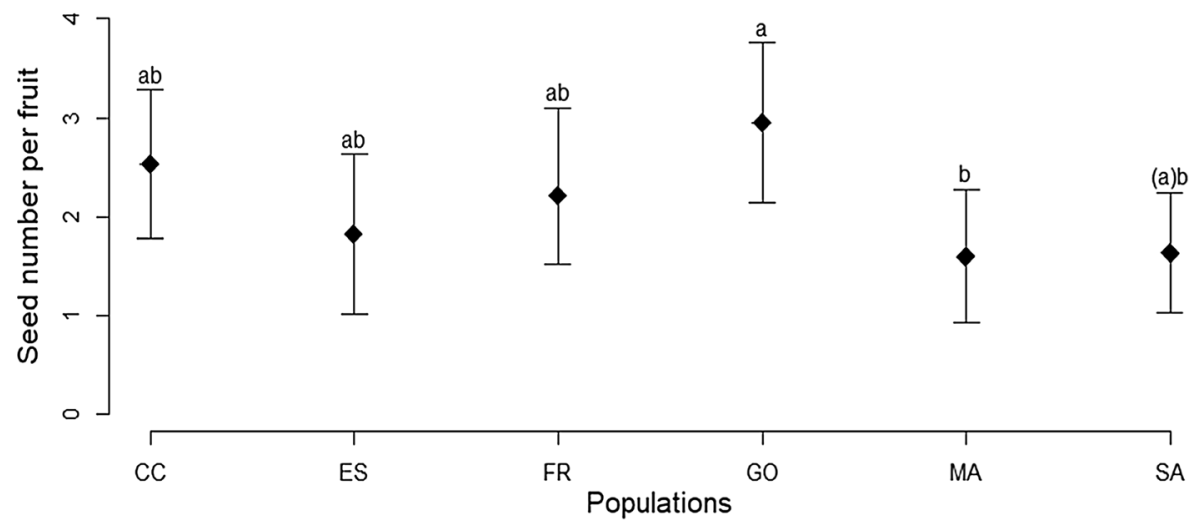

(b)

Fig. 5 a Mean number of fruits per plant and $\mathbf{b}$ Mean number of seeds per fruit of $A$. tragacantha according to the populations. Vertical bars represent the $95 \%$ confidence interval. $C C$ Cap Croisette population, $E S$ Escalette population, FR Frioul island population, $G O$ Goudes population, $M A$ Marseilleveyre population, $S A$ Saména population; "a,b" $=t$ test significant difference between the populations; the parenthesis indicates a marginal significance

populations. The third feature was that the pollinator abundance, but not the richness, positively influenced the plant reproductive success.

\section{Contrasted mating system among populations}

Our results on controlled pollination treatments highlighted that A. tragacantha was very lowly self-fertile (values close to 0 ), i.e., was not autogamous self-pollinating. This species thus was pollinator-dependent for its reproduction. Similarly, Astragalus exscapus is not self-fertile and depends on bumblebee activity to produce fruits and seeds (Becker et al. 2011), and Astragalus nitidiflorus is a facultative outcrossing species (Martínez-Sánchez et al. 2011). We showed that A. tragacantha is completely selfcompatible. Such self-compatibility associated with selfing may lead to an inbreeding depression, especially in fragmented populations (Fahrig 2003; Aguilar et al. 2008, 


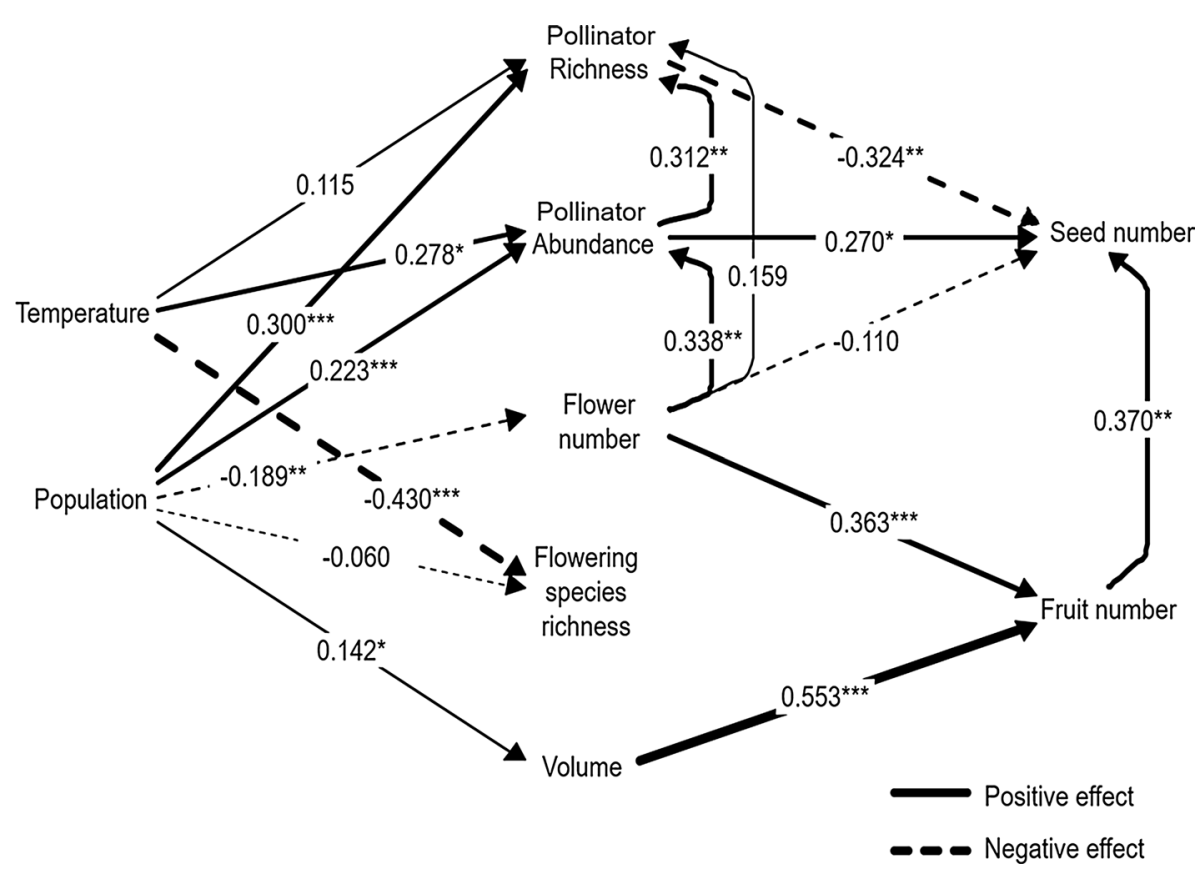

Fig. 6 Path diagram tested by structural equation modelling (i.e., structural equation modelling, SEM; Lefcheck 2016) for $A$. tragacantha reproduction strategy (Fisher's $C=47.52, k=36, p>0.05$ ). The width of the arrows depends on the size of the effect. ***p $<0.001 ; * * p<0.01 ; * \mathrm{p}<0.05$. See the Supplementary Material 3 for the details of the path coefficients and the settings of the path-analysis. The "temperature" was in ${ }^{\circ} \mathrm{C}$, the "volume" was the plant volume $\left(\mathrm{m}^{3}\right)$, the "flowering species richness" was the number of flowering species in the $8 \mathrm{~m}^{2}$ patch around observed plants, the "flower number" was the total number of flowers per observed plant, the "abundance" was the number of pollinator per observed plant, the "richness" was the number of morphogroups per observed plant, the "fruit number" was the total number of fruits per observed plant, and the "seed number" was the mean number of seeds per fruit

Becker et al. 2011). Inbreeding depression has already been demonstrated in Astragalus exscapus (Becker et al. 2011) and Astragalus peckii in greenhouse conditions (Martin 2010). Among our studied populations, only the GO population showed a significant inbreeding depression while the CC, SA and FR populations did not. Conversely, the $\mathrm{CC}$ population, which presented the largest number of empty fruits, showed a lower reproductive success for between-population crossings when it crosses with MA and GO populations, i.e., outbreeding depression. Similarly, Becker et al. (2011) showed evidence of outbreeding depression in A. exscapus populations. We showed that these depressions occurred simultaneously. Consequently, further work could be needed on the consequences of between-population crossings and on the effects of the interaction of inbreeding and outbreeding depressions using molecular markers (Edmands 2007). Inbreeding and outbreeding depressions decreasing the reproductive success, they could be a part of the population decline of A. tragacantha in Calanques National Park (Crnokrak and Roff 1999, Frankham et al. 2011, Charlesworth and Charlesworth 2012). Finally, this plant species did not show pollen limitation as already shown in Astragalus peckii (Martin 2010), meaning that pollinators are as efficient as manual pollinations. Thus, the contrasted performance in selfing and outcrossing within and among populations supports the existence of a mixed mating system in the A.tragacantha species. We 


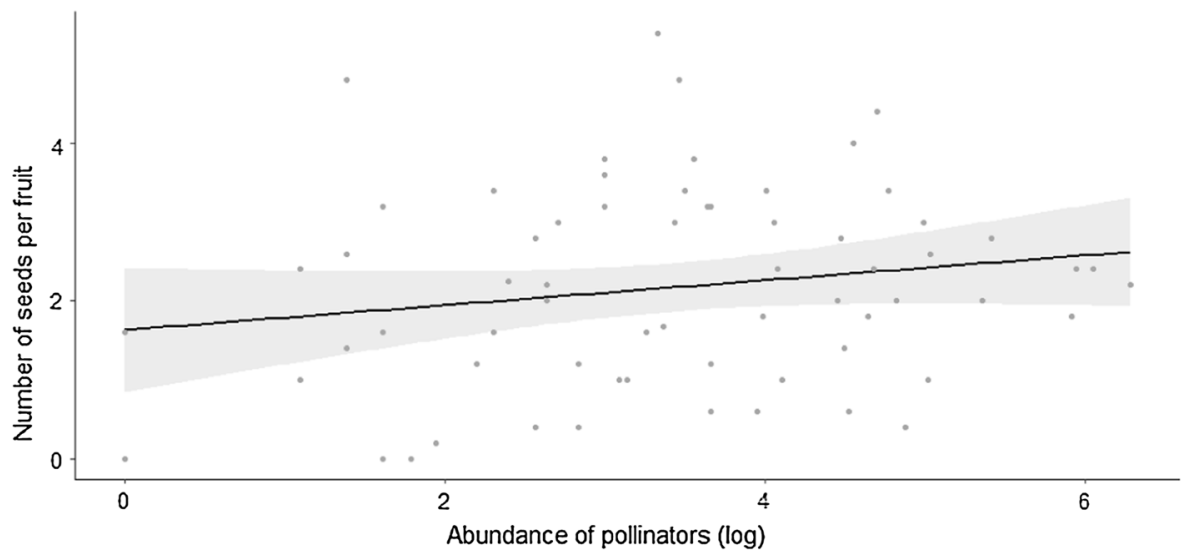

(a)

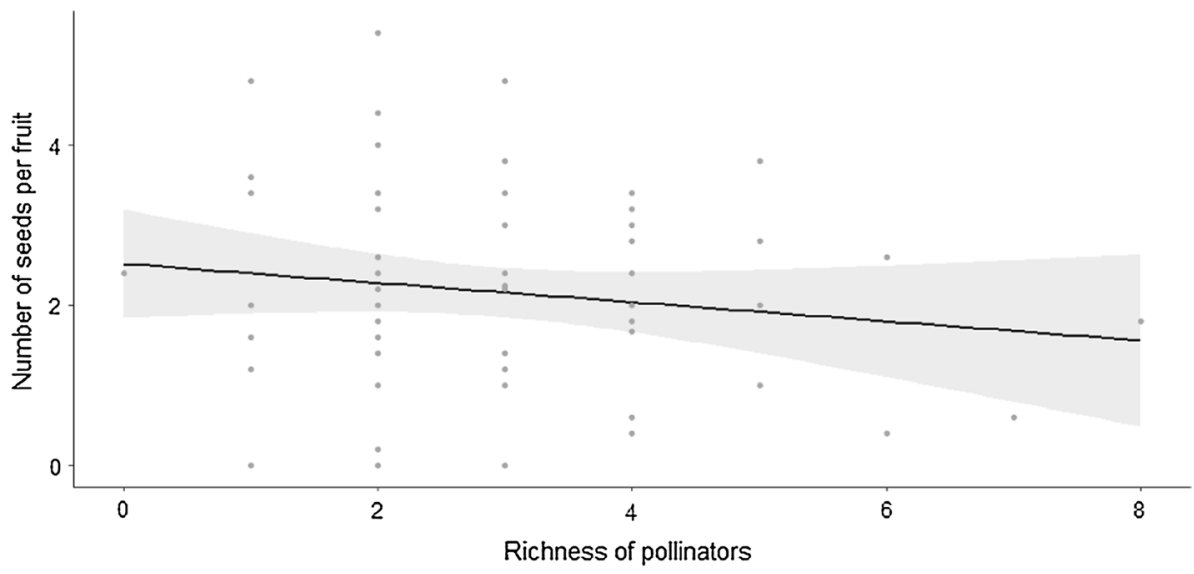

(b)

Fig. 7 Mean number of seeds per fruit according to the a pollinator abundance and $\mathbf{b}$ pollinator richness per plant. The line represents the mean, and the grey areas represent the $95 \%$ confidence interval

hypothesized that contrasted performances could be linked to the pollinator guild of $A$. tragacantha.

\section{Contrasted pollinator activity among populations}

\section{Pollinator community structure}

Among our studied populations, the pollinator observations and captures showed differences in the pollinator community composition. According to the path-analysis results, these differences in pollinator abundance and richness were not linked with the flowering plant species richness or abundance. They were thus uncorrelated with the availability of local resources even if previous studies have shown that pollinator communities are usually mediated by attractive plant species with high rewards and greater floral display size 
(Westphal et al. 2003; Karron et al. 2004; Martin 2010; Torné-Noguera et al. 2014). These differences could be explained by the landscape complexity which might have had an influence on the structure of the pollinator community (Shackelford et al. 2013). The pollinator community might also have been influenced by local effects through the presence of a nesting substrate e.g., snail shells or bare soil areas (Torné-Noguera et al. 2014).

Furthermore, we showed that the $\mathrm{CC}$, GO and FR populations were mostly linked to a single pollinating species: a predominance of Anthophora plumipes in the CC population, Eucera caspica in the FR population (solitary species), and Bombus terrestris in the GO population (social species). We hypothesized that this preponderance of a few species might have consequences on pollen dispersion especially because of the variations in foraging behavior notably linked to pollinator body size (Gathmann and Tscharntke 2002). The Eucera and Anthophora genera present the same morphological and behavioral characteristics. They comprise long-tongued species (species with large mouthparts) particularly adapted to the collection of rewards in A. tragacantha flowers. Bombus terrestris is a generalist species (i.e., foraging on a wide variety of flowers), with high floral constancy (Cresswell 1999). This species is known to forage in the same plant or among the nearest neighboring plants (Manning 1956; Geslin et al. 2014).

\section{Pollinator impact on reproductive success}

The pollinator observations showed a positive significant influence of pollinator abundance on the total number of seeds per fruit. This result was not surprising as the positive link between pollinator abundance and seed quantity and fruit quality has been often demonstrated (e.g., Morandin and Winston 2005; Klein et al. 2007; Geslin et al. 2017).

However, contrary to our expectations, the increase in pollinator richness was negatively linked with the number of seeds per fruit. This result was unexpected because pollinator richness is generally shown to improve the seed set (Klein et al. 2007; Hoehn et al. 2008) even if among all the flower visitors only a few truly play a role in plant reproduction i.e., legitimate pollinator tripping the flower (Ollerton 2017; Bauer et al. 2017). However, a flower of A. tragacantha having a keel covering the stamens, it is possible that once opened by a nonlegitimate visitor species, it becomes less attractive to legitimate pollinators as a signal that the flower has already been visited. So, an increase in pollinator richness might increase the probability of receiving a nonlegitimate visit, decreasing per se the reproductive success. The increase of the number of seeds per fruit can result from more flowers being tripped. Then, the different species can lead to different tripping rate with a variation in the pollen deposition and pollen removing (Bauer et al. 2017). To correctly identify the legitimate pollinator, an additional experiment should be performed. We suggest observing untripped flowers and waiting for an interaction between a pollinator (from a single species) and a flower. Pollinator performance between species would be subsequently compared through a) their contribution to stigmatic pollen deposition and pollen tube growth and b) the seed set of visited flowers (Ne'Eman et al. 2010; Alonso et al. 2011).

\section{Contrasted reproductive success among $A$. tragacantha populations}

Despite of the $20 \%$ of empty fruits, our study showed significant differences in the plant reproductive success among populations. Indeed, the GO, CC and FR populations, especially GO, presented higher seed sets than the ES, SA and MA populations. These three first populations also showed single species preponderances (i.e., B. terrestris in the GO 
population, A. plumipes in the CC population, and E. Caspica in the FR population) compared to the others three populations with no dominant species. In that respect, we hypothesized that the specific foraging behavior of pollinators could be linked with the contrasted performances in selfing and/or outcrossing (Mitchell et al. 2009). Indeed, pollination fundamentally determines the maximum frequency and diversity of mating opportunities (Harder and Barrett 1996). Moreover, the differences in pollination patterns according to pollinator species influences the effective distance over which pollen is dispersed, influencing plant reproductive success (Ne'eman et al. 2006).

Both pollinators, A. plumipes and E. caspica, seemed to regularly switch between individuals within the same population (pers. obs., L. Schurr). This behavior has already been shown especially for neotropical Anthophoridae (Frankie et al. 1976). Furthermore, no Eucera have been observed to visit thyme, cistus and rosemary in Calanques National Park during the same flowering period (pers. com., L. Ropars). Eucera caspica could be a legitimate efficient pollinator (Ollerton 2017) of A. tragacantha. This "switching" foraging behavior made by A. plumipes and E. caspica might favor outcrossed pollinations and the long-term reproduction of this rare plant species.

Meanwhile, B. terrestris has been observed foraging in A. tragacantha, between flowers on the same plant (i.e., geitonogamous selfing; Lloyd and Schoen 1992) or among the nearest neighboring plants showing a known high floral constancy (Manning 1956; Geslin et al. 2014). Thus, as previously shown by Karron et al. (2009), we hypothesized that the foraging behavior of bumblebees could favor individual selfing. Indeed, bumblebees have already been described to accomplish self-pollinations in Astragalus exscapus (Becker et al. 2011). As we showed that autogamous selfing is very low in A. tragacantha, geitonogamous selfing may be the preponderant mode of selfing for this plant species. Furthermore, the preponderance of $B$. terrestris in the GO population could have contributed to the existence of inbreeding depression (Manning 1956; Karron et al. 2009; Becker et al. 2011; Geslin et al. 2014). We suggest that the link between pollinator foraging behavior and specific pollen flow should be tested with fluorescent powders and/or genetic markers in the plant populations (see for example Frankie et al. 1976; Guiller et al. 2016).

Finally, between-population crossings might not be beneficial as we showed that these crossings, especially with the CC population, can lead to a lower reproductive success. However, the distances between most of the plant populations $(350 \mathrm{~m}$ to $9 \mathrm{~km}$ with a mean of $3.5 \mathrm{~km} \pm 2,5 \mathrm{~km}$ ) suggest that $A$. tragacantha pollinators could not actually forage among the populations (Gathmann and Tscharntke 2002; Zurbuchen et al. 2010). A threshold distance value between its populations (i.e., an optimal outcrossing distance) could exist for which individual performances would be less affected by outcrossed pollinations (Oostermeijer et al. 1995).

\section{Astragalus tragacantha population management}

Our study provides important information with regards to the preservation and restoration of A. tragacantha populations, particularly in the context of the inbreeding and outbreeding depression risks (Edmands 2007). In that way, the reconnection actions of the fragmented A. tragacantha populations must be achieved while favoring outcrossed pollinations within population. Furthermore, a management experiment is planned through the translocation of seedlings to reinforce existing populations and create reintroduction sites. Then, these results are useful to resolve the question of seed origin and mixture. Simultaneously, as some populations have pollinator distinctiveness, a case-by-case management approach 
must be considered, particularly for marginal populations. All of these features must be taken into account to ensure the efficiency of restoration actions and for the conservation of the integrity of A. tragacantha pollinator networks and reproduction and the conservation of other Mediterranean and Atlantic phryganas.

Acknowledgements We are thankful to Calanques National Park for financial support. We thank A. Baumel for its helpful advices. We are grateful to D. Genoud, M. Aubert and D. Pavon for bee and plant identifications, and to L. Ropars for her support in the field. We thank the two English proofreadings of the manuscript (M. Paul REF 0820L025171 and 'American Journal Expert': Certificate Verification Key: 9EEDCE9D-8AE4-6522-49C3). Finally, we show gratitude to the two anonymous reviewers that provided useful comments on original version of the manuscript.

\section{References}

Affre L, Dumas P-J, Dumas E et al (2015) Regard écologique sur le recul stratégique: atouts et risques pour la diversité végétale péri- urbaine marseillaise. Vertigo Hors série 21:13p

Agren J, Schemske DW (1993) Outcrossing rate and inbreeding depression in two annual monoecious herbs, Begonia Hirsuta and Begonia Semiovata. Evolution (NY) 47:125-135. https://doi.org/10.2307/24101 23

Aguilar R, Quesada M, Ashworth L et al (2008) Genetic consequences of habitat fragmentation in plant populations: susceptible signals in plant traits and methodological approaches. Mol Ecol 17:51775188. https://doi.org/10.1111/j.1365-294X.2008.03971.x

Aizen MA, Ashworth A, Galetto L (2002) Reproductive success in fragmented habitats: do compatibility systems and pollination specialization matter? J Veg Sci 13:885-892. https://doi. org/10.1111/J.1654-1103.2002.Tb02118.X

Åkesson M, Liberg O, Sand H et al (2016) Genetic rescue in a severely inbred wolf population. Mol Ecol 25:4745-4756. https://doi.org/10.1111/mec.13797

Alonso C, Herrera CM, Ashman T (2011) A piece of the puzzle: a method for comparing pollination quality and quantity across multiple species and reproductive events. New Phytol 193:532-542

Barnosky AD, Hadly EA, Bascompte J et al (2012) Approaching a state shift in Earth's biosphere. Nature 486:52-58. https://doi.org/10.1038/nature11018

Bauer AA, Clayton MK, Brunet J (2017) Floral traits influencing plant attractiveness to three bee species: consequences for plant reproductive success. Am J Bot 104:772-781. https://doi.org/10.3732/ ajb. 1600405

Becker T, Voss N, Durka W (2011) Pollen limitation and inbreeding depression in an "old rare" bumblebeepollinated grassland herb. Plant Biol 13:857-864. https://doi.org/10.1111/j.1438-8677.2011.00452.x

Campagne P, Affre L, Baumel A et al (2008) Fine-scale response to landscape structure in Primula vulgaris Huds.: does hedgerow network connectedness ensure connectivity through gene flow? Popul Ecol 51(1):209-219. https://doi.org/10.1007/s10144-008-0124-2

Charlesworth D, Charlesworth B (2012) Inbreeding depression and its evolutionary consequences. Annu Rev Ecol Evol Syst 18:237-268

Cresswell JE (1999) The influence of nectar and pollen availability on pollen transfer by individual flowers of oil-seed rape (Brassica napus) when pollinated by bumblebees (Bombus lapidarius). J Ecol 87:670677. https://doi.org/10.1046/j.1365-2745.1999.00385.x

Crnokrak P, Roff DA (1999) Inbreeding depression in the wild. Heredity (Edinb) 83:260-270. https://doi. org/10.1038/sj.hdy.6885530

Dick CW, Hardy OJ, Jones FA et al (2008) Spatial scales of pollen and seed-mediated gene flow in tropical rain forest trees. Trop Plant Biol 1:20-33. https://doi.org/10.1007/s12042-007-9006-6

Edmands S (2007) Between a rock and a hard place: evaluating the relative risks of inbreeding and outbreeding for conservation and management. Mol Ecol 16:463-475. https://doi.org/10.1111/j.1365294X.2006.03148.x

Fahrig L (2003) Effects of habitat fragmentation on biodiversity. Rev Lit Arts Am 34:487-515. https://doi. org/10.1146/132419

Frankham R (2015) Genetic rescue of small inbred populations: meta-analysis reveals large and consistent benefits of gene flow. Mol Ecol 24:2610-2618. https://doi.org/10.1111/mec.13139

Frankham R, Ballou JD, Eldridge MDB et al (2011) Predicting the probability of outbreeding depression. Conserv Biol 25:465-475. https://doi.org/10.1111/j.1523-1739.2011.01662.x 
Frankham R, Bradshaw CJA, Brook BW (2014) Genetics in conservation management: revised recommendations for the 50/500 rules, Red List criteria and population viability analyses. Biol Cons 170:56-63

Frankie GW, Opler PA, Bawa KS (1976) Foraging Behaviour of Solitary Bees: implications for outcrossing of a neotropical forest tree. Br Ecol Soc 64:1049-1057

Gathmann A, Tscharntke T (2002) Foraging ranges of solitary bees. J Anim Ecol 71:757-764. https:// doi.org/10.1046/j.1365-2656.2002.00641.x

Geslin B, Baude M, Mallard F et al (2014) Effect of local spatial plant distribution and conspecific density on bumble bee foraging behaviour. Ecol Entomol 39:334-342. https://doi.org/10.1111/een.12106

Geslin B, Aizen MA, Garcia N et al (2017) The impact of honey bee colony quality on crop yield and farmers' profit in apples and pears. Agric Ecosyst Environ 248:153-161. https://doi.org/10.1016/j. agee.2017.07.035

Guiller C, Affre L, Albert CH et al (2016) How do field margins contribute to the functional connectivity of insect-pollinated plants? Landsc Ecol. https://doi.org/10.1007/s10980-016-0359-9

Harder LD, Barrett SCH (1996) Pollen dispersal and mating patterns in animal-pollinated plants. In: Lloyd DG, Barrett SCH (eds) Floral biology. Springer, Boston

Hardion L, Baumel A, Dumas P et al (2010) Phylogenetic relationships and infrageneric classification of Astragalus tragacantha L. (Fabaceae), inferred from nuclear ribosomal DNA Internal transcribed spacers data (nrDNA ITS). Ecol Mediterr 36:99-106

Hardion L, Dumas PJ, Abdel-Samad F et al (2016) Geographical isolation caused the diversification of the Mediterranean thorny cushion-like Astragalus L. sect. tragacantha DC. (Fabaceae). Mol Phylogenet Evol 97:187-195. https://doi.org/10.1016/j.ympev.2016.01.006

Hoehn P, Tscharntke T, Tylianakis JM et al (2008) Functional group diversity of bee pollinators increases crop yield. Proc Biol Sci 275(1648):2283-2291. https://doi.org/10.1098/rspb.2008.0405

Johnson WE, Onorato DP, Roelke ME et al (2010) Genetic restoration of the Florida panther. Science 329:1641-1645. https://doi.org/10.1126/science.1192891

Karron JD, Mitchell RJ, Holmquist KG et al (2004) The influence of floral display size on selfing rates in Mimulus ringens. Heredity (Edinb) 92:242-248. https://doi.org/10.1038/sj.hdy.6800402

Karron JD, Holmquist KG, Flanagan RJ et al (2009) Pollinator visitation patterns strongly influence amongflower variation in selfing rate. Ann Bot 103:1379-1383. https://doi.org/10.1093/aob/mcp030

Klein A-M, Vaissiere BE, Cane JH et al (2007) Importance of pollinators in changing landscapes for world crops. Proc R Soc B Biol Sci 274:303-313. https://doi.org/10.1098/rspb.2006.3721

Laffont-Schwob I, Dumas PJ, Pricop A et al (2011) Insights on metal-tolerance and symbionts of the rare species Astragalus tragacantha aiming at phytostabilization of polluted soils and plant conservation. Ecol Mediterr 37(2):57-62

Lefcheck JS (2016) piecewiseSEM: piecewise structural equation modelling in $r$ for ecology, evolution, and systematics. Methods Ecol Evol 7:573-579. https://doi.org/10.1111/2041-210X.12512

Lloyd DG, Schoen DJ (1992) Self- and cross-fertilization in plants. I-functional dimensions. Int J Plant Sci 153:358-369

Manning A (1956) Some aspects of the foraging behaviour of bumble-bees. Behaviour 9:164-201

Martin EF (2010) Reproduction, demography, and habitat characterization of Astragalus peckii (Fabaceae), a Rare Central Oregon Endemic. Dissertation, University of Oregon State University

Martínez-Sánchez JJ, Segura F, Aguado M et al (2011) Life history and demographic features of Astragalus nitidiflorus, a critically endangered species. Flora Morphol Distrib Funct Ecol Plants 206:423-432. https://doi.org/10.1016/j.flora.2010.11.006

Médail F, Myers N (2004) Mediterranean basin. In: Mittermeier RA, Gil PR, Hoffmann M et al (eds) Hotspots revisited: Earth's biologically richest and most endangered terrestrial ecoregions. CEMEX, Monterrey, Conservation International, Washington and Agrupación Sierra Madre, Mexico, pp 144-147

Médail F, Quézel P (1999) Biodiversity hotspots in the Mediterranean basin: setting global conservation priorities. Conserv Biol 13:1510-1513

Mitchell RJ, Irwin RE, Flanagan RJ et al (2009) Ecology and evolution of plant-pollinator interactions. Ann Bot 103:1355-1363. https://doi.org/10.1093/aob/mcp122

Morandin LA, Winston ML (2005) Wild bee abundance and seed production in conventional, organic, and genetically modified canola. Ecol Appl 15:871-881

Ne'eman G, Shavit O, Shaltiel L et al (2006) Foraging by male and female solitary bees with implications for pollination. J Insect Behav 19:383-401. https://doi.org/10.1007/s10905-006-9030-7

Ne'eman G, Andreas J, Newstrom-Lloyd L et al (2010) A framework for comparing pollinator performance: effectiveness and efficiency. Biol Rev 85:435-451. https://doi.org/10.1111/j.1469-185X.2009.00108.X

Ogilvie JE, Griffin SR, Gezon ZJ et al (2017) Interannual bumble bee abundance is driven by indirect climate effects on floral resource phenology. Ecol Lett 20:1507-1515. https://doi.org/10.1111/ele.12854 
Ollerton J (2017) Pollinator diversity: distribution, ecological function, and conservation. Annu Rev Ecol Evol Syst 48:353-376

Oostermeijer JGB, Altenburg RGM, Den Nijs HCM (1995) Effects of outcrossing distance and selfing on fitness components in the rare Gentiana pneumonanthe (Gentianaceae). Acta Bot Neerl 44:257-268. https://doi.org/10.1111/j.1438-8677.1995.tb00784.x

Salducci MD, Folzer H, Issartel J et al (2019) How can a rare protected plant cope with the metal and metalloid soil pollution resulting from past industrial activities? Phytometabolites, antioxidant activities and root symbiosis involved in the metal tolerance of Astragalus tragacantha. Chemosphere 217:887-896. https://doi.org/10.1016/j.chemosphere.2018.11.078

Schemske DW, Lande R (1985) The evolution of self-fertilization and inbreeding depression in plants. II. Empirical observations. Evolution (NY) 39:41. https://doi.org/10.2307/2408515

Shackelford G, Steward PR, Benton TG et al (2013) Comparison of pollinators and natural enemies: a metaanalysis of landscape and local effects on abundance and richness in crops. Biol Rev 88:1002-1021. https://doi.org/10.1111/brv.12040

Shipley B (2009) Confirmatory path analysis in a generalized multilevel context. Ecology 90:363-368. https ://doi.org/10.1890/08-1034.1

Shipley B (2013) The AIC model selection method applied to path analytic models compared using a d-separation test. Ecology 94:560-564. https://doi.org/10.1890/12-0976.1

Suehs CM, Affre L, Medail F (2005) Unexpected insularity effects in invasive plant mating systems: the case of Carpobrotus (Aizoaceae) taxa in the Mediterranean Basin. Biol J Linn Soc 85:65-79

Tallmon DA, Luikart G, Waples RS (2004) The alluring simplicity and complex reality of genetic rescue. Trends Ecol Evol 19:489-496. https://doi.org/10.1016/j.tree.2004.07.003

R Core Team (2017) R: a language and environment for statistical computing. R Foundation for Statistical Computing, Vienna. https://www.R-project.org/

Terzo M, Rasmont P (2016) Clé des genres d'apoïdes d'Europe Occidentale. Unpublished

Torné-Noguera A, Rodrigo A, Arnan X et al (2014) Determinants of spatial distribution in a bee community: nesting resources, flower resources, and body size. PLoS ONE 9:1-10. https://doi.org/10.1371/ journal.pone.0097255

Valsecchi F (1994) Sul complesso Astragalus tragacantha L. (Leguminosae) nel Mediterraneo. Webbia 49:31-41

Westphal C, Steffan-Dewenter I, Tscharntke T (2003) Mass flowering crops enhance pollinator densities at a landscape scale. Ecol Lett 6:961-965. https://doi.org/10.1046/j.1461-0248.2003.00523.x

Whiteley AR, Fitzpatrick SW, Funk WC, Tallmon DA (2015) Genetic rescue to the rescue. Trends Ecol Evol 30:42-49. https://doi.org/10.1016/j.tree.2014.10.009

Wilcove DS, McLellan CH, Dobson AP (1986) Habitat fragmentation in the temperate zone. Conserv Biol Sci Scarcity Divers 11:237-256

Willi Y, Fischer M (2005) Genetic rescue in interconnected populations of small and large size of the selfincompatible Ranunculus reptans. Heredity (Edinb) 95:437-443

Zurbuchen A, Landert L, Klaiber J et al (2010) Maximum foraging ranges in solitary bees: only few individuals have the capability to cover long foraging distances. Biol Conserv 143:669-676. https://doi. org/10.1016/j.biocon.2009.12.003 